\title{
Patient counseling, risk factors and comorbidity assessment in diabetic foot ulcer
}

\author{
Smithamol SUNNY ${ }^{1}$ (D), Swathy PRADEEP 1 (D), Anita ANN SUNNY 1 (D), Rama PARTHASARATHY ${ }^{1}$ (D) \\ Shanmugasundaram RAJESHKUMAR 2 (D), Sankar VEINTRAMUTHU 3 * (D) \\ 1 Department of Pharmacy Practice, PSG College of Pharmacy, Coimbatore, India 641004 \\ 2 Department of Surgery, PSG Hospitals, PSG Instiute of Medical Sciences and Research, Coimbatore, India 641004 \\ 3 Department of Pharmaceutics, PSG College of Pharmacy, Coimbatore, India 641004 \\ * Corresponding author. E-mail: sansunv@yahoo.co.in (S.V.); Tel. +91-422-4345841; Fax. +91-422-2594400.
}

Received: 02 July 2018 / Revised: 17 September 2018 / Accepted: 16 October 2018

ABSTRACT: Diabetic foot ulcer usually develops due to lack of knowledge and awareness regarding the consequences of the disease progression and poor foot care among diabetics. The objective of the study is to enhance knowledge, attitude and clinical practice among diabetic foot ulcer patients through pharmacist counseling, and to assist physician in the selection of cost effective antibiotics. Data on the disease condition such as duration of illness, type of diabetes, category of infections, classification of foot ulcer, risk factors, comorbidities and antibiotics used were collected and analyzed. Additionally, the details of culture sensitivity report for sensitive and resistant microorganisms with respect to antibiotics were recorded. Appropriate patient education on diabetic foot ulcer helps to improve their knowledge, attitude, and practice significantly. The commonest microbial isolates identified in diabetic foot ulcer patients were Klebsiella pneumonia, Pseudomonas aeruginosa and Staphylococcus aureus. Culture sensitive drugs found were meropenem, amoxicillin with clavulanic acid, clindamycin and the resistant drugs were cefepime, levofloxacin and penicillin.

KEYWORDS: Diabetic foot ulcer; patient counseling; risk factors; comorbidity; culture sensitivity.

\section{INTRODUCTION}

Diabetic foot is one of the most significant and devastating complication of diabetes. World Health Organization (WHO 1985), defines diabetic foot ulcer as an infection, ulceration and/or destruction of deep tissues associated with neurological abnormalities and various degrees of peripheral vascular disease in the lower limb. Most of the diabetic foot ulcer patients delay in approaching health care facilities with advanced foot ulcers because of financial worries, poor awareness \& inadequate diabetes healthcare which may lead to a non-healing ulcer that causes severe damage to tissues and bone, requiring surgical removal (amputation) of a toe, foot or part of a leg. Foot ulcers significantly contribute to morbidity and mortality of patients with diabetes mellitus [1]. Even though preventive strategies have been shown to be cost-effective, diabetic foot ulcers still occur frequently and are a challenge for the individual and for the health system.

Management of diabetic foot ulcers requires a sequence of routine evaluation and thorough preventive maintenance. Studies state that patient education regarding foot hygiene, nail care and proper footwear is crucial in reducing foot ulcer occurrence by $50 \%$ and amputations by up to $85 \%$. The aim of the study is to educate, enhance compliance with proper foot care guidance, assess the risk factors, comorbidities in diabetic foot ulcer patients and to focus on the importance of choosing selective cost effective brands of antibiotics for treatment.

\section{RESULTS AND DISCUSSION}

A total of 96 patients were included in the study, of which, majority of the patients falls under the age group of $60-80$ years $(71 \%) \&$ male patients were more in number. Most of the male patients aged between 60 80 years had DM for $\geq 10$ years (64\%). These findings are similar to other studies, which showed that diabetic foot problem is a major concern among the elderly people which increases the morbidity in them due to diabetes. It is well understood that diabetic foot disease occurs in long standing diabetic foot disease because

How to cite this article: Sunny S, Pradeep S, Ann Sunny A, Parthasarathy R, Rajeshkumar S, Veintramuthu S. Patient counseling, risk factors and comorbidity assessment in diabetic foot ulcer. J Res Pharm. 2019; 23 (2): 298-303. 
the pathological process takes about 10 years to develop. Majority of the patients were admitted with moderate conditions of the disease. A large majority of the patients were employed (69 patients $72 \%$ ) and only (45 patients $47 \%$ ) received physician's assessment. Most of them were presented with cellulitis (42 patients $44 \%$ ). Out of 96 patients 22(24\%) reported single comorbid disease state and $74(77 \%)$ multiple comorbid disease conditions. Commonly observed comorbid disease conditions were hypertension (52), dyslipidemia (41), heart disease (12) and renal disease (9) (Figure 1). Knowledge, attitude and practice level was assessed through KAP questionnaire.

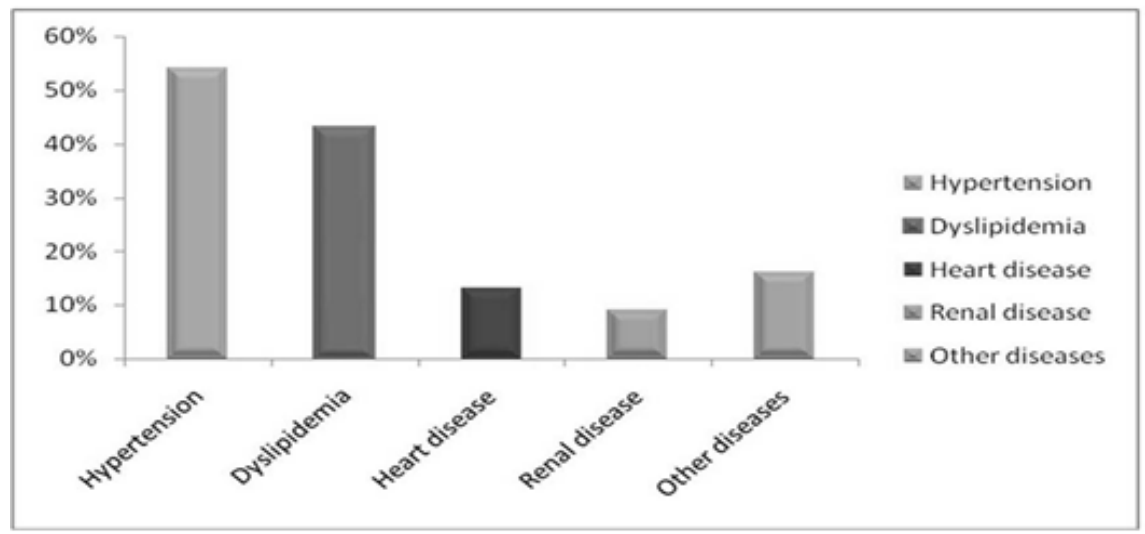

Figure 1. Comorbid disease conditions in diabetic foot ulcer patient.

The study reveals that the majority of patients admitted for diabetic foot infections had poor knowledge as well as poor foot care practice. Although patients had a particular level of foot care knowledge, the practice of proper foot care was not always carried out [2]. Knowledge, practice and attitude showed significant difference by improvement after counselling session. The findings were similar to other related studies in the practice of foot care, pre survey results was always poorer than the patient foot care knowledge assessment score of the post survey [3]. Association between demographic variables with knowledge, attitude and practice, and comparision of pre and post patient counseling KAP in diabetic foot ulcer patients was carried out using paired $T$ test. Significant $p$-value $(\mathrm{p}<0.05)$ difference was shown between pre and post survey analysis in knowledge and attitude. Practice level also showed high significance (Table 1).

Table 1. Analysis of Knowledge, Attitude and Practice (Pre and Post).

\begin{tabular}{|c|c|c|c|c|c|c|c|c|c|c|c|}
\hline \multicolumn{4}{|c|}{ Knowledge } & \multicolumn{4}{|c|}{ Attitude } & \multicolumn{4}{|c|}{ Practice } \\
\hline $\begin{array}{l}\text { Educational } \\
\text { level }\end{array}$ & Pre & Post & $\begin{array}{l}\text { \#Impr } \\
\text { oved }\end{array}$ & $\begin{array}{l}\text { Educational } \\
\text { level }\end{array}$ & Pre & Post & $\begin{array}{l}\text { \#Impro } \\
\text { ved }\end{array}$ & $\begin{array}{l}\text { Educational } \\
\text { level }\end{array}$ & Pre & Post & $\begin{array}{l}\text { \#Impro } \\
\text { ved }\end{array}$ \\
\hline Poor & $47 \%$ & $5 \%$ & $42 \%$ & Unfavorable & $55 \%$ & $4 \%$ & $51 \%$ & Poor & $60 \%$ & $8 \%$ & $52 \%$ \\
\hline Satisfactory & $41 \%$ & $46 \%$ & $5 \%$ & Favorable & $47 \%$ & $96 \%$ & $49 \%$ & Satisfactory & $35 \%$ & $48 \%$ & $13 \%$ \\
\hline Good & $13 \%$ & $49 \%$ & $36 \%$ & & & & & Good & $4 \%$ & $44 \%$ & $40 \%$ \\
\hline
\end{tabular}

\#paired t-test $(\mathrm{p}<0.05)$

Our study supports the fact that, educational programs improve the foot care performance of diabetic patients. Peripheral neuropathy (76 \%) was the commonly observed risk factor in the study subjects, which was followed by hypertension (54 \%), smoking (50\%), alcohol consumption (43\%) and dyslipidemia (43\%), which are modifiable risk factors (Figure 2). 


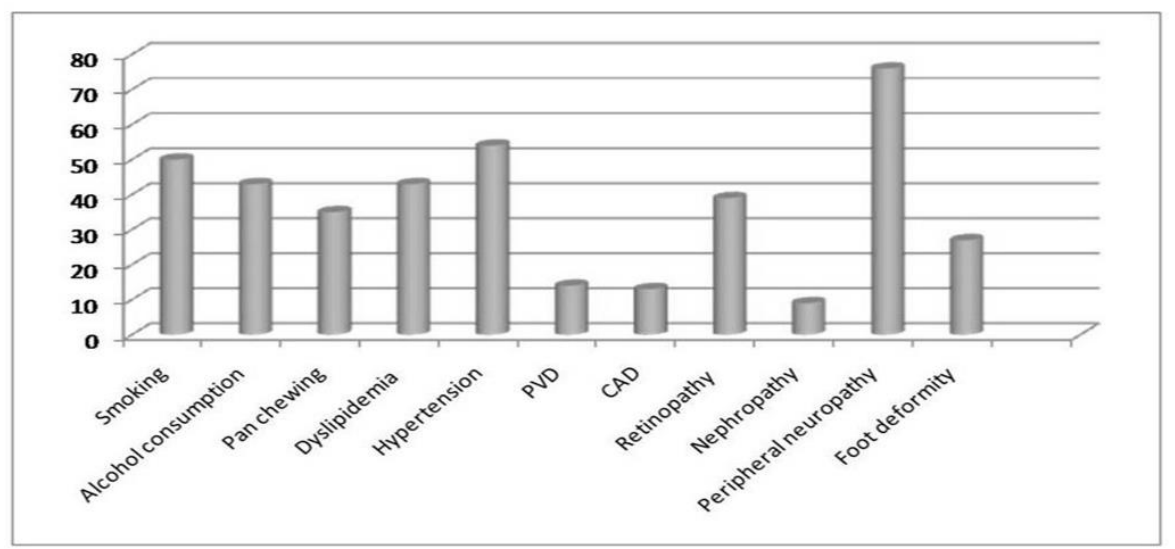

Figure 2. Common risk factors observed in diabetic foot ulcer patients.

Longer duration of diabetes, increased age and uncontrolled diabetes leads to peripheral neuropathy, and it is one of the major risk factor for foot ulcer [4]. Male patients were of greater percentage in our study and are a category at risk because of the habits such as alcohol consumption, smoking and pan chewing which increase the intensity of disease risk which has been observed in previous studies. Majority of the respondents reported comorbid disease condition, and the presence of multiple comorbidities were on the higher side. Hypertension and dyslipidaemia were the major comorbidities that were reported, and this finding was also observed in our results. A total of 10 microbial isolates were obtained from diabetic foot ulcer patients. The commonest isolates were Klebsiella pneumonia (20 \%), Pseudomonas aeruginosa (20 \%) and Staphylococcus aureus (20\%) (Figure 3).

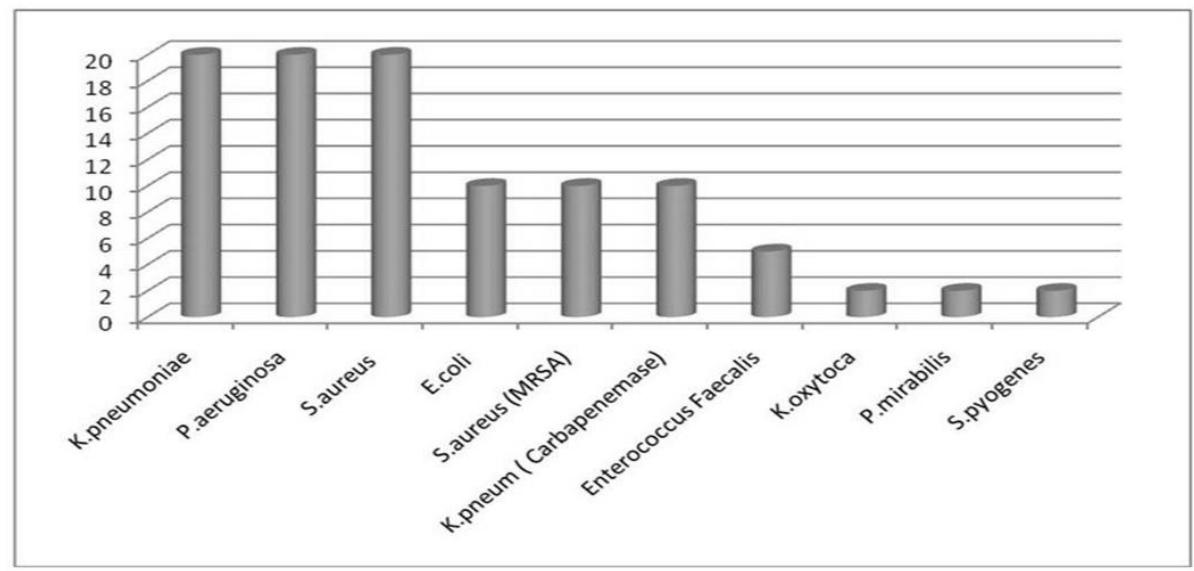

Figure 3. Microbial isolates from diabetic foot ulcer patients.

Culture sensitive drugs found were meropenem, amoxicillin+clavulanic acid, clindamycin and the resistant drugs were cefepime, levofloxacin and penicillin. Management of diabetic foot ulcers with antibiotic therapy based on culture sensitivity tests is necessary for proper disease management. The cheapest drugs were identified by comparing various brands with dose per unit, under each generic class of drugs. The brand names were renamed to mask the identity. $\mathrm{A}$ and $\mathrm{B}$ denote the brands of meropenem, $\mathrm{C}$ and $\mathrm{D}$ represent the brands of amoxicillin+clavulanic acid, E and F specify the brands of imipenem, G and H state the brands of clindamycin, I and J mention the brands of ceftriaxone, $\mathrm{K}$ and $\mathrm{L}$ describe the brands of linezolid, $\mathrm{M}$ and $\mathrm{N}$ denote the brands of levofloxacin, and $\mathrm{O}$ and $\mathrm{P}$ represent the brands of piperacillin+tazobactam. The cost ratio (Figure 4) for each brand was found out using the formula: Cost ratio =(highest price / lowest price). Among the antibiotics (all were injections except levofloxacin were given as tablet form) highest cost ratio was found for levofloxacin tablet $500 \mathrm{mg}$ and ceftriaxone injection $250 \mathrm{mg}$ and $500 \mathrm{mg}$. 


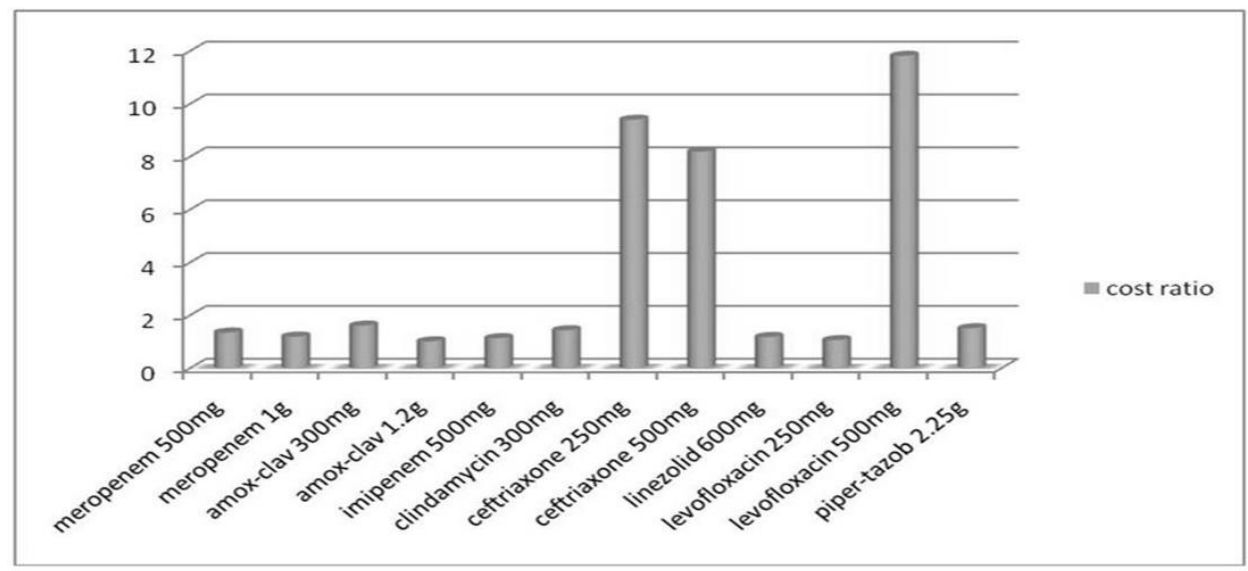

Figure 4. Cost ratio of various antibiotics used.

The cost ratio of levofloxacin tablet was 11.81. This indicates that the costliest brand of levofloxacin is 11.81 times more expensive than the cheapest brand. The medical expenses associated with antibiotics use per patient were found to be high (Table 2). The average antibiotic cost of patient stayed in the hospital for $\leq 10$ days was found to be 2141.32 ( 68 patients), $\leq 20$ days was 2133.60 ( 25 patients) and $\leq 30$ days was 21,706.8 ( 3 patients). This is because of improper care.

Table 2. Assessment of total expenses of diabetic foot ulcer.

\begin{tabular}{llllll}
\hline Si.no & Length of stay & No of patients & $\begin{array}{l}\text { Total antibiotic } \\
\text { cost in INR }\end{array}$ & $\begin{array}{l}\text { Other drug cost } \\
\text { in INR }\end{array}$ & $\begin{array}{l}\text { Other cost in } \\
\text { INR }\end{array}$ \\
\hline 1. & $\leq 10$ days & 68 & 5754.33 & 2141.32 & 1346.32 \\
2. & $\leq 20$ days & 25 & 7329.93 & 2133.60 & 1500.8 \\
3. & $\leq 30$ days & 3 & $58,613.53$ & $21,706.8$ & 14120 \\
\hline
\end{tabular}

From the above data it is evident that the average antibiotic expenses per patient increase proportionally with length of hospital stay, even though uniform numbers of patients were not obtained in each category to get precise results in this aspect. Our results are similar to the results of [5], where they specify that the highest costs per patient were for hospitalization, antibiotics, amputations and other surgical procedures which can be minimised with proper management which will reduce the length of hospitalisation and also the economic burden for the patients. Physicians can consult clinical pharmacists in brand selection to minimize the antibiotic expenses for patients.

\section{CONCLUSION}

Patient counseling is an important element in patient care process. Educating the patients with respect to diabetic foot ulcer plays an important role in improving the knowledge, attitude, and practice significantly and besides, it may reduce the length of stay in the hospital. Choosing cost effective brands of antibiotics can reduce the medical expenses for the patients. More efforts are stringently needed to educate the public about risk factors, complications, prevention and management of diabetic foot ulcers.

\section{MATERIALS AND METHODS}

\subsection{Study site and population}

Open labelled and interventional study was conducted in the department of General Surgery in a multispecialty hospital. The study was carried out for a period of 8 months. The study protocol was submitted to Institutional Human Ethics Committee (IHEC, PSGIMSR) of the Hospital, and it was approved with proposal number: $14 / 023$. Patients satisfying the study inclusion criteria were enrolled in the study after obtaining informed consent. A total of 126 patients were screened and of these, 96 patients with diabetic foot ulcer were included and the remaining subjects with varicosities, vasculitic ulceration and ulcers other than foot ulcer were excluded from the study. 


\subsection{Methodology and data collection}

Patient demographics, details of the disease conditions and antibiotics prescribed were collected. The various sources for data collection comprise of Knowledge, Attitude and Practice [KAP] questionnaire, lab investigation reports including culture sensitivity tests and the details of prescribed antibiotics, comorbidities, and risk factors collected from the medical records. Data from medical records were collected at baseline and at the follow-up visits. Antimicrobial susceptibility test was performed in the hospital by disc diffusion technique according to Clinical and Laboratory Standards Institute guidelines. The details of culture sensitivity report for sensitive and resistant microorganism with respect to antibiotics were recorded in terms of dose, dosage, duration \& route of administration. KAP questionnaire was provided to the patient during the initial visit after which counselling was provided for diabetic foot care (as per the recommendations of National Programme for Prevention \& Control of Cancer, Diabetes, Cardiovascular Disease \& Stroke [NPCDCS], India) and a follow up KAP questionnaire assessment was done to assess the improvement in foot care. KAP questionnaire is shown in (Table 3). Follow up review was done after 1 week/ 2 weeks/one month/ directly through telephone in order to assess the knowledge and practice.

Table 3. Knowledge, attitude and practice questionnaire on diabetic foot ulcer.

\begin{tabular}{|c|c|c|}
\hline S.No & Parameter & Questions \\
\hline 1. & Knowledge Assessment: & $\begin{array}{l}\text { 1. Is it true that all patients with diabetes develop reduced blood } \\
\text { flow in their feet? } \\
\text { 2. Is it true that all patients with diabetes develop foot ulcer? } \\
\text { 3. Is it true that all patients with diabetes develop gangrene? } \\
\text { 4. Were you given any information regarding foot care? If yes, } \\
\text { when? } \\
\text { 5. Are you aware that smoking can reduce blood flow in your feet? } \\
\text { 6. Do you know that if you have loss of sensation on your foot, you } \\
\text { are more prone to have foot ulcers? } \\
\text { 7. Do you know that if you have reduced blood flow on your foot, } \\
\text { you are more prone to get foot ulcers? } \\
\text { 8. Is it true that all patients with diabetes develop lack of sensations } \\
\text { in their feet? } \\
\text { 9. Do you know that if you have foot infection, you will develop foot } \\
\text { wounds? } \\
\text { 10. Which do you think is appropriate way of trimming your nail? } \\
\text { Cutting along the edges/cutting straight through? }\end{array}$ \\
\hline
\end{tabular}

2. Attitude Assessment:

1. Are you willing to change your foot habits and do regular exercise to prevent further complications due to diabetes?

2. Do you think people with diabetes should take the responsibility of self-foot examinations like checking sole of foot daily/wearing podiatrist prescribed foot wear/consulting podiatrist regularly? 3. Are you willing to use special foot wear prescribed by your podiatrist?

4. Will you wear foot wear indoors as advised by your podiatrist?

5. Do you think you can lead a normal life if you take appropriate measures for diabetes?

3. Practice Assessment: 1. Do you wash your feet daily?

2. Do you moisturize dry areas of your feet daily?

3. Do you check your feet daily for any injury?

4. What would you do if you find any abnormality on your feet?

You manage yourself/consult a podiatrist?

5. Are you toeing nails by cutting straight through regularly?

6. Do you check whether your shoes/socks leave marks on your feet?

7. How often do you change your foot wear? When slippers are damaged/once in a year/more than once in a year?

8. How often do you go for foot check-up? Once in a month/once in 6 months/once in a year/only during illness? 


\subsection{Statistical analysis}

All data analyses were performed GraphPad Prism (version 5, California, USA). A significance level of 0.05 was considered as statistical significance. Data were expressed as mean \pm SD. The Student's t-test was done to compare the pre and post-test in KAP in diabetic foot ulcers.

Ethical Approval: All procedures performed were in accordance with the ethical standards of the institution. Formal consent is obtained from the patients.

Acknowledgement: We would like to thank Principal, PSG College of Pharmacy, Dr S Premkumar, Department of surgery, PSG Hospitals, Clinical sites and the patients for their participation. We also thank Dr Sivaram Hariharan, for his extensive English proof reading and editing services.

Author contributions: Concept -V.S., S.S.R., S.S.; Design -V.S., S.S.R.,S.P., S.S.; Supervision -V.S Resource - S.S., S.S.R., P.R; Materials - S.S., S.P., A.A.S.; Data Collection and/or Processing - S.S., S.P., A.A.S., V.S.; Analysis and/or Interpretation - S.S., V.S.; Literature Search - S.S., S.P., A.A.S.; Writing - S.S., S.P., A.A.S.; Critical Reviews -S.S., P.R., SP., A.A.S ., V.S.

Conflict of interest statement: The author reports no conflicts of interest. The author alone is responsible for the content and writing of the article.

\section{REFERENCES}

[1] Tentolouris N, Boulton AJM, Al-Sabbagh S, Jude EB, Walker MG. Mortality in diabetic \& non- diabetic patients after amputations performed from 1990-1995-5 year follow up study. Diabetes Care. 2004; 27(7): 1598-1604. [CrossRef]

[2] Desalu OO, Salawu FK, Jimoh AK, Adekoya AO. Diabetic foot care: Self-reported knowledge and practice among patients attending three tertiary hospitals in Nigeria. Ghana Med J. 2011; 45(2): 60-65. [CrossRef]

[3] Kafaie P, Noorbala MT, Soheilikhah S, Rashidi M. Evaluation of patients' education on foot self-care status in diabetic patients. Iran Red Crescent Med J. 2012; 14(12) 829-832. [CrossRef]

[4] Lavery LA, Armstrong DG, Wunderlich RP, Mohler MJ, Wendel CS, Lipsky BA. Risk factors for foot infections in individuals with diabetes. Diabetes Care. 2006; 29(6) 1288-1293. [CrossRef]

[5] Prompers L, Huijberts M, Schaper N, Apelqvist J, Bakker K, Edmonds M, Holstein P, Jude E, Jirkovska A, Mauricio D, Piaggesi A, Reike H, Spraul M, Van Acker K, Van Baal S, Van Merode F, Uccioli L, Urbancic V, Ragnarson Tennvall G. Resource utilisation and costs associated with the treatment of diabetic foot ulcers. Prospective data from the Eurodiale study. Diabetologia. 2008; 51(10): 1826-1834. [CrossRef] 